\title{
BMJ Open The impact of functional limitations on long-term outcomes among African-American and white women with breast cancer: a cohort study
}

\author{
Monika Izano, ${ }^{1}$ William A Satariano, ${ }^{2}$ Robert A Hiatt, ${ }^{1,3}$ Dejana Braithwaite ${ }^{1,3}$
}

To cite: Izano M,

Satariano WA, Hiatt RA, et al. The impact of functional limitations on long-term outcomes among

African-American and white women with breast cancer: a cohort study. BMJ Open 2013;3:e003232.

doi:10.1136/bmjopen-2013003232

\section{- Prepublication history and} additional material for this paper is available online. To view these files please visit the journal online (http://dx.doi.org/10.1136/ bmjopen-2013-003232).

Received 17 May 2013 Revised 24 July 2013 Accepted 27 August 2013

\footnotetext{
${ }^{1}$ Department of Epidemiology and Biostatistics, University of California, San Francisco, California, USA

${ }^{2}$ School of Public Health, University of California, Berkeley, California, USA ${ }^{3}$ Helen Diller Family Comprehensive Cancer Center, University of California, San Francisco, California, USA
}

Correspondence to Dr Dejana Braithwaite; DBraithwaite@epi.ucsf.edu

\section{ABSTRACT}

Objectives: We examined the impact of functional limitations and functional decline during the first year following breast cancer diagnosis on the risk of mortality from breast cancer and other causes among African-American and white women, respectively.

Design: The Health and Functioning in Women (HFW) cohort study.

Setting: Detroit, Michigan, USA.

Participants: A total of 162 African-American and 813 white women aged 40-84 years with newly diagnosed breast cancer identified through the Metropolitan Detroit Cancer Surveillance System over a 7-month period between 1984 and 1985 and followed for up to 28 years (median 11 years).

Outcome measures: Risk of mortality from breast cancer and other causes.

Results: Statistically significant increases in the risk of other-cause mortality were found for each unit increase in the number of self-reported functional limitations (HR=1.08, $95 \% \mathrm{Cl} 1.03$ to 1.14 ), 0 vs $\geq 1$ functional limitations ( $\mathrm{HR}=1.47,95 \% \mathrm{Cl} 1.13$ to 1.91 ), difficulty in pushing or pulling large objects ( $H R=1.34$, $95 \% \mathrm{Cl} 1.04$ to 1.73 ), writing or handling small objects ( $\mathrm{HR}=1.56,95 \% \mathrm{Cl} 1.00$ to 2.44 ), and walking half a mile (HR=1.60, 95\% Cl 1.19 to 2.14).

Functional limitations and functional decline did not explain racial disparities in the survival of this cohort. Functional decline was associated with increased risk of other-cause mortality in women with regional and remote disease but not in women with localised disease. Whereas measures of functional limitation were not associated with breast cancer-specific mortality, each unit of functional decline ( $H R=1.17$, $95 \% \mathrm{Cl} 1.05$ to 1.31 ) and decline in the ability to sit $\geq 1 \mathrm{~h}$ ( $\mathrm{HR}=2.06,95 \% \mathrm{Cl} 1.13$ to 3.76 ) were associated with increased risk of breast cancerspecific mortality. Measures of functional decline were associated with increased risk of breast cancer mortality in overweight and obese women, but not in women of normal weight.

Conclusions: Whereas functional limitations were associated with increased risk of other-cause mortality, functional decline was associated with increased risk of breast cancer mortality.

\section{ARTICLE SUMMARY}

Strengths and limitations of this study

- This study used comprehensive measures of functional limitations and functional decline, and a prospective population-based cohort design.

- The HFW cohort contains of a relatively large set of white and African-American participants, a long follow-up and multiple covariates in the tumour-related, lifestyle and sociodemographic domains.

- A major limitation of this study is that the majority of respondents were treated with partial or radical mastectomy, which is no longer the standard of care for early-stage breast cancer.

\section{INTRODUCTION}

Functional limitations at the time of breast cancer diagnosis and following initial treatment have been associated with a number of adverse outcomes among breast cancer survivors. ${ }^{1-4}$ Summary measures of physical functioning have been previously evaluated among breast cancer survivors. ${ }^{256}$ Yet the prognostic value of individual limitations versus summary measures of physical functioning and functional decline remains poorly understood. Primary treatment causes functional decline in some patients with breast cancer, ${ }^{7-9}$ and while most recover, some older women do not and may decline even further. ${ }^{10} 11$ While functional decline in the first 2 years after breast cancer diagnosis has been related to 10-year survival among women with breast cancer, ${ }^{12}$ its impact on longer term survival has not been evaluated. It is also unclear whether any differences in physical functioning exist among population subgroups. For example, older African-American patients with breast cancer have been shown to have a disproportionately increased comorbidity burden compared with their white counterparts, but it is unknown whether they also have more limitations in physical functioning. A better 
understanding of the role of functional limitations and functional decline may provide opportunities to reduce mortality among breast cancer survivors through targeted interventions within high-risk populations. ${ }^{13}$

In this study of the long-term prognostic role of functional limitations and functional decline, we considered death from breast cancer and other causes in a cohort of African-American and white breast cancer survivors from the Health and Functioning in Women (HFW) study. ${ }^{5} \mathrm{~A}$ wide age range, the inclusion of both African-American and white women and a median follow-up of 11 years make this cohort particularly suitable for examining racial disparities and the long-term effect of functional limitations and functional decline while taking into account a wide range of clinical, lifestyle-related and sociodemographic prognostic factors. We hypothesised that the presence of functional limitations in the first few months after breast cancer diagnosis and the subsequent decline in functional status over the first year would be associated with increased risk of mortality. As disparities in the survival of African-American and white women continue to exist, ${ }^{14} 15$ we also wished to evaluate whether they could be accounted for in part by functional limitations. Obesity is a significant contributor to survival disparities among patients with breast cancer, ${ }^{16}$ as well as being an important prognostic factor in postmenopausal women. ${ }^{17} 18$ Furthermore, although functional limitations have been associated with tumour stage, ${ }^{19}$ the extent to which disease severity affects the impact of functional limitations on mortality is not well understood. ${ }^{2}$ Therefore, we also examined the extent to which the impact of functional limitations on mortality differed as a function of tumour stage and body mass index (BMI).

\section{METHODS}

\section{Study population}

The HFW study used in the present analysis has been previously described. ${ }^{5}{ }^{6}$ Briefly, the HFW study was established in 1984 in the Detroit metropolitan area to assess the health, functional and psychosocial status of women following breast cancer diagnosis. A total of 1011 eligible participants aged 40-84 years with newly diagnosed, histologically confirmed, primary invasive breast cancer identified through the Metropolitan Detroit Cancer Surveillance System (MDCSS) at the Michigan Cancer Foundation, now the Barbara Ann Karmanos Cancer Institute, within 4 weeks of diagnosis, were interviewed in two cohorts. The first cohort consisted of 571 participants aged 55-84 years who were identified over a 7-month period between 1984 and 1985; of these, $463(81.1 \%)$ were successfully interviewed between 2 and 4 months following diagnosis. A second cohort of 620 eligible cases, ages 40-54 and 74-84 years, was identified over a 7-month period between 1987 and 1988; 548 $(88.4 \%)$ of these participants were successfully interviewed between 2 and 4 months after diagnosis, henceforth referred to as the baseline interview or month 3 interview. All participants were interviewed a second time approximately
9 months after the first interview, henceforth referred to as the month 12 interview. The two cohorts were combined and 975 women, for whom complete data were available on all key variables, were included in this analysis.

\section{Functional limitation assessment}

Respondents were asked at 3-month and 12-month interviews whether they experienced difficulty in performing any of the physical tasks described by $\mathrm{Nagi}^{20}$ : (1) pushing or pulling large objects; (2) stooping, crouching or kneeling; (3) lifting objects weighing less than 10 pounds; (4) lifting objects weighing more than 10 pounds; (5) reaching or extending arms above or below shoulder level; (6) writing or handling small objects; (7) standing longer than $15 \mathrm{~min}$; (8) sitting longer than an hour; (9) going up or down a flight of stairs; and (10) walking half a mile. ${ }^{5}{ }^{6}$ A woman was considered to have a functional limitation if she reported that the task was completed with a lot of difficulty or avoided on doctor's orders. ${ }^{6}$ In this analysis, we considered (1) the effect of individual functional limitations reported at the baseline interview, (2) the effect of the number of functional limitations reported at the 3-month interview as a continuous predictor and (3) also the effect of a binary predictor indicating the presence of any functional limitation at the 3-month interview ( $\geq 1$ functional limitations vs 0 ) on mortality in order to evaluate a non-linear relationship. We also separately considered the association of three measures of functional decline between the first and second interviews with mortality. These measures were (1) binary predictors of developing a specific functional limitation between the 3-month and 12-month interviews, (2) the number of functional limitations first reported at the month 12 interview as a continuous predictor and (3) a binary indicator of any newly reported functional limitations ( $\geq 1$ vs 0 ), henceforth referred to as functional decline.

\section{Covariates}

The covariates used in this analysis were sociodemographic, lifestyle-related and clinical prognostic factors that, based on the existing literature and a priori reasoning, could potentially confound associations between functional limitations and mortality outcomes. Information on age at diagnosis, breast cancer stage, breast cancer treatment, tumour size and node involvement was obtained from the MDCSS file, while information on other variables was obtained from interviews. In analyses, age was used as a continuous variable. Race was coded as either African-American or white. Years of education were recoded into four categories: less than high school, high school, college and graduate. The dataset included a binary indicator of financial adequacy ( 0 for adequate and 1 for inadequate) that was based on selfreported current financial resources and whether they met the participant's needs. ${ }^{6}$ BMI was calculated as weight in kilograms/height in $\mathrm{m}^{2}$ or $\mathrm{kg} / \mathrm{m}^{2}$, from self- 
reported weight and height at the baseline interview and used as a continuous variable in multivariate models. Smoking status was self-reported and recoded as a binary indicator of whether the participant was a smoker at the time of the interview. A comorbidity index was constructed as the number of previously diagnosed conditions reported by the respondent at the baseline interview from a list of 23 conditions that included diabetes, hypertension, stroke, heart disease, gastrointestinal disease, liver conditions and primary cancers other than breast cancer, which according to the respondent currently caused some limitation in her activities. ${ }^{6}$

Stage of breast cancer at diagnosis was coded as local, regional or remote. In addition to information on surgery (no surgery, partial mastectomy or modified radical mastectomy) provided by the MDCSS files, physicians completed a supplementary survey regarding chemotherapy and hormonal therapy administered on an outpatient basis. However, adjuvant therapy utilisation has been shown to be under-reported in SEER registries, ${ }^{21}$ resulting in a small number of participants with evidence of chemotherapy and/or hormonal therapy treatment in addition to partial or radical mastectomy. Less than 30 women received no surgery. We combined data from the MDCSS files and physician surveys to create a two-level treatment variable (no surgery or partial mastectomy, and modified radical mastectomy). The log of the tumour size in millimetres was centred around its mean and used as a continuous variable. The number of positive lymph nodes involved was recoded into a three-level variable ( 0 nodes, $1-3$ nodes and $\geq 4$ nodes).

\section{Endpoint ascertainment}

Participants were followed until last contact or death as assessed during April 2012, whichever occurred first. Date and cause of death, classified by the International Classification of Diseases (ICD) codes V.9, were identified through annual vital status surveillance of all patients in the registry, conducted by MDCSS. ${ }^{22}$ ICD codes 174.0-174.9 represented breast cancer deaths and other ICD codes represented death from causes other than breast cancer referred to henceforward as othercause mortality.

\section{Statistical analysis}

Racial differences between continuous variables were assessed using Student $\mathrm{t}$ test and between categorical variables were assessed by Pearson $\chi^{2}$ or Fisher's exact test when the counts were small. Racial differences in sample medians were assessed using the Wilcoxon Rank Sum test. Kaplan-Meier plots were used to examine the association between functional limitations and mortality and $\mathrm{p}$ values for log-rank tests are provided in the appendix. Cox proportional hazards models with time since diagnosis as the time scale were employed to estimate the association between measures of functional limitation and other-cause and breast cancer mortality. ${ }^{23}$ In multivariable models, interaction terms were considered. Risk was expressed as HR and 95\% CI. The proportionality of hazards assumption was assessed using Schoenfeld residuals. ${ }^{24}$ These tests revealed significant departures from proportionality. Therefore, models were stratified by age at breast cancer diagnosis. For analyses involving death from breast cancer, participants who died from other causes were removed from the cohort at the time of their death and vice versa. Treatment, tumour stage, tumour size, node involvement, race, BMI, financial adequacy, education, smoking status and period of entry were considered as potential confounders in all multivariate analyses. To evaluate effect modification, we conducted analyses separately for subgroups defined by BMI $(<25,25-30$ and $>30)$ at the baseline interview and stage of breast cancer (local, regional or remote) at diagnosis. We combined women in the regional and remote categories due to the small number of respondents with remote disease $(n=55)$. The type I error was set at 0.05 and all reported $p$ values are two sided. Analyses were conducted in SAS V.9.2 (SAS Institute, Cary, North Carolina, USA) and R V.2.15.

\section{RESULTS}

The demographic and clinical characteristics of African-American $(\mathrm{n}=162 ; 16.6 \%)$ and white women $(\mathrm{n}=813 ; 83.3 \%)$ with breast cancer are presented in table 1 . Overall, the median follow-up time was 11 years (IQR 4.522.4 years). Median follow-up was significantly shorter for African-American women than their white counterparts (median=9 years (IQR 3.0-19.0) vs 12 years (IQR 4.8-22.7), $\mathrm{p}=0.0003$ ). Among those who survived, African-American women $(\mathrm{n}=28)$ and white women $(\mathrm{n}=193)$ had similar follow-up (median $=24.3$ years vs 24.4 years, $\mathrm{p}=0.07$ ), which suggests that the difference in median survival between African-American and white women is due to increased mortality among African-American women. During this period, there were 753 deaths; 317 were due to breast cancer and 436 were due to other causes. Slightly more African-American women died of breast cancer than white women $(37.7 \%$ vs $31.5 \%, \mathrm{p}=0.13)$. There were no racial differences in the proportion of other-cause deaths $(44.4 \%$ vs $44.8 \%, \mathrm{p}=0.94)$. The distribution of age was also similar in both groups. Compared with white women, African-American women had significantly fewer years of education ( $24.7 \%$ vs $28.3 \%$, respectively, had $\geq 12$ years of education; $\mathrm{p}<0.0001)$, greater mean BMI $\left(28.2 \mathrm{~kg} / \mathrm{m}^{2}\right.$ vs $\left.25.9 \mathrm{~kg} / \mathrm{m}^{2}, \mathrm{p}<0.0001\right)$, and fewer reported adequate financial resources $(66.7 \%$ vs $86 \%$, respectively; $\mathrm{p}<0.0001)$. African-American women were less likely than their white counterparts to have localised disease $(43.8 \%$ vs $55.6 \%$, respectively; $\mathrm{p}=0.01$ ) at the time of breast cancer diagnosis. Additionally, African-American women were more likely to have regional disease $(48.1 \%$ vs $39.2 \%$, respectively; $\mathrm{p}=0.04)$, receive no surgery ( $3.7 \%$ vs $1.4 \%$, respectively; $\mathrm{p}=0.04$ ), and have larger tumours, with mean tumour sizes of $38.2(\mathrm{SD}=26.2)$ and $32.8(\mathrm{SD}=24.7)$ millimetres for African-American and white women, respectively $(\mathrm{p}=0.01)$. 
Table 1 Characteristics of the study group overall and by race

\begin{tabular}{|c|c|c|c|c|}
\hline & $\begin{array}{l}\text { Overall } \\
\mathrm{N}=975\end{array}$ & $\begin{array}{l}\text { African-American } \\
\mathrm{N}=162\end{array}$ & $\begin{array}{l}\text { White } \\
\mathrm{N}=813\end{array}$ & p Value \\
\hline Age at diagnosis, mean \pm SD & $63 \pm 12.4$ & $62.5 \pm 12.6$ & $63.1 \pm 12.4$ & 0.59 \\
\hline Follow-up (years), Median (Q1, Q3) & $11(4.5,22.4)$ & $9(3,19)$ & $12(4.8,22.7)$ & 0.0003 \\
\hline Financial adequacy & $807(82.8)$ & $108(66.7)$ & $699(86)$ & $<0.0001$ \\
\hline \multicolumn{5}{|l|}{ Highest level of educational attainment, $\mathrm{N}(\%)$} \\
\hline Less than high school & $375(38.5)$ & $89(54.9)$ & $286(35.2)$ & \multirow[t]{4}{*}{$<0.0001$} \\
\hline High school & 330 (33.8) & $33(20.4)$ & $297(36.5)$ & \\
\hline College & $210(21.5)$ & 32 (19.8) & $178(21.9)$ & \\
\hline Graduate & $60(6.2)$ & $8(4.9)$ & $52(6.4)$ & \\
\hline Body mass index $\left(\mathrm{kg} / \mathrm{m}^{2}\right)$, mean $\pm S D$ & $26.3 \pm 5.3$ & $28.2 \pm 5.4$ & $25.9 \pm 5.1$ & $<0.0001$ \\
\hline \multicolumn{5}{|l|}{ Stage, N (\%) } \\
\hline Local & $523(53.6)$ & $71(43.8)$ & $452(55.6)$ & 0.01 \\
\hline Regional & $397(40.7)$ & $78(48.1)$ & $319(39.2)$ & 0.04 \\
\hline Remote & $55(5.6)$ & $13(8)$ & $42(5.2)$ & 0.15 \\
\hline Smoking, N (\%); current smokers & $195(20)$ & $37(22.8)$ & $158(19.4)$ & 0.32 \\
\hline \multicolumn{5}{|l|}{ Breast cancer treatment, $\mathrm{N}(\%)$} \\
\hline No surgery & $17(1.7)$ & $6(3.7)$ & $11(1.4)$ & 0.04 \\
\hline Partial mastectomy & $194(19.9)$ & $29(17.9)$ & $165(20.3)$ & 0.49 \\
\hline Modified radical mastectomy & $760(77.9)$ & $126(77.8)$ & $634(78)$ & 0.95 \\
\hline \multicolumn{5}{|l|}{ Number of lymph nodes involved, N (\%) } \\
\hline 0 & $443(45.4)$ & $60(37)$ & $383(47.1)$ & \multirow[t]{3}{*}{0.10} \\
\hline $1-3$ & $302(31)$ & $57(35.2)$ & $245(30.1)$ & \\
\hline$\geq 4$ & $39(4)$ & $10(6.2)$ & $29(3.6)$ & \\
\hline Tumour size $(\mathrm{mm})$, mean \pm SD & $33.7 \pm 25$ & $38.2 \pm 26.2$ & $32.8 \pm 24.7$ & 0.01 \\
\hline Comorbidity index, mean \pm SD & $2.2 \pm 1.5$ & $2.2 \pm 1.6$ & $2.2 \pm 1.5$ & 0.91 \\
\hline \multicolumn{5}{|l|}{ Functional limitations at 3 months after breast cancer diagnosis } \\
\hline Number of functional limitations, mean \pm SD & $2.2 \pm 2.3$ & $2.8 \pm 2.3$ & $2.1 \pm 2.3$ & 0.0003 \\
\hline$\geq 1$ functional limitation, $\mathrm{N}(\%)$ & $682(69.9)$ & $135(83.3)$ & $547(67.3)$ & $<0.0001$ \\
\hline \multicolumn{5}{|l|}{ Functional decline between baseline and 12 months } \\
\hline $\begin{array}{l}\text { Number of functional limitations at month } 12 \text { but not at month } 3 \text {, } \\
\text { mean } \pm S D\end{array}$ & $0.4 \pm 1$ & $0.6 \pm 1.4$ & $0.4 \pm 0.9$ & 0.03 \\
\hline$\geq 1$ additional functional limitation reported at month $12, \mathrm{~N}(\%)$ & $212(21.7)$ & $36(22.2)$ & $176(21.6)$ & 0.87 \\
\hline \multicolumn{5}{|l|}{ Mortality, N (\%) } \\
\hline All cause & $753(77.3)$ & $133(82.6)$ & $620(76.3)$ & 0.08 \\
\hline Breast cancer specific & $317(32.5)$ & $61(37.7)$ & $256(31.5)$ & 0.13 \\
\hline Other cause & $436(44.7)$ & $72(44.4)$ & $364(44.8)$ & 0.94 \\
\hline
\end{tabular}

The distributions of summary measures of functional limitations overall and by race are presented in table 1 and distributions of specific functional limitations are presented in figure 1A,B. At 3 months after breast cancer diagnosis, African-American women were more likely to report any functional limitations $(83.3 \%$ vs $67.3 \%$, $\mathrm{p}<0.0001)$ and a greater number of functional limitations than their white counterparts (mean $2.8(\mathrm{SD}=2.3)$ and 2.1 $(\mathrm{SD}=2.3) ; \mathrm{p}=0.0003)$. African-Americans were more likely than whites to report difficulty in pushing or pulling large objects $(66.1 \%$ vs $48 \%, \mathrm{p}<0.0001)$, lifting less than 10 pounds $(33.3 \%$ vs $19.3 \%, \mathrm{p}<0.0001)$, lifting more than 10 pounds $(62.4 \%$ vs $42.9 \%, \mathrm{p}<0.0001)$, going up or down a flight of stairs $(17.3 \%$ vs $11.7 \%, \mathrm{p}=0.05)$, and walking half a mile $(29.6 \%$ vs $22.1 \%, \mathrm{p}=0.04)$. In addition to having a greater mean increase in the number of functional limitations during the first year after diagnosis $(0.6$ $(\mathrm{SD}=1.4)$ vs $0.4(\mathrm{SD}=0.9), \mathrm{p}=0.03)$, a larger proportion of African-American women reported difficulty going up or down a flight of stairs at month 12 but not at month 3 (16.7\% vs $9 \%, \mathrm{p}=0.003)$.

\section{Other-cause mortality}

Comparing white women with versus without functional limitations, Kaplan-Meier plots show considerably shorter other-cause survival for those with functional limitations (figure 2A, p value for log-rank test $<0.0001$, appendix). Overall, African-American women with or without functional limitations have shorter survival times than their white counterparts. Borderline statistically significant differences were observed in the survival curves of African-American women with functional limitations and their white counterparts ( $p$ value for log-rank test=0.06). Difficulties in pushing or pulling large objects $(\mathrm{HR}=1.34,95 \%$ CI 1.04 to 1.73$)$, writing or handling small objects $(\mathrm{HR}=1.56,95 \%$ CI 1.00 to 2.44$)$, walking half a mile $(\mathrm{HR}=1.60,95 \% \mathrm{CI} 1.19$ to 2.14$)$, each unit increase in the number of self-reported 
Figure 1 (A) Distribution of functional limitations reported at 3 months following breast cancer diagnosis. (B) Distribution of functional decline between 3 and 12 months following breast cancer diagnosis.
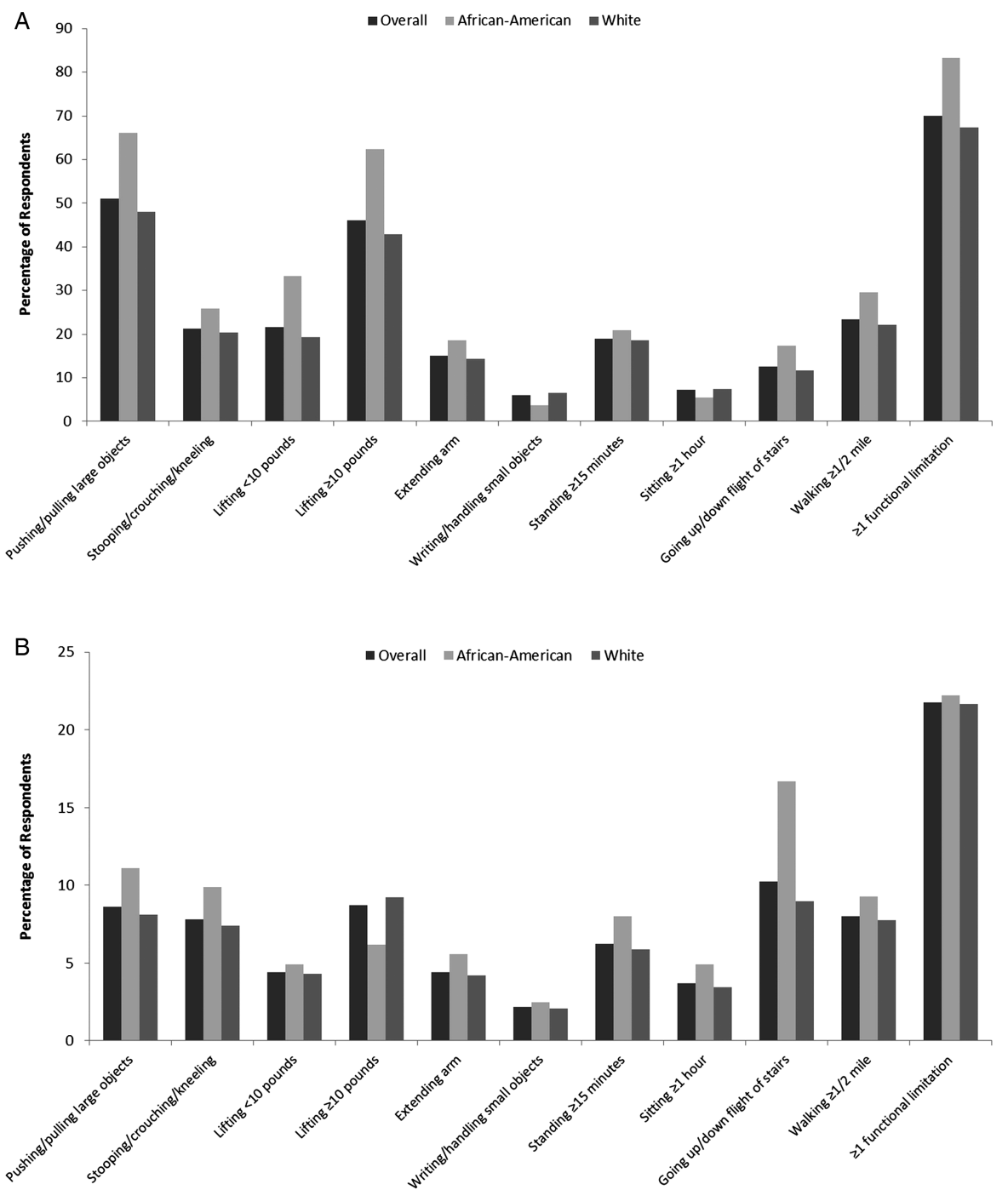

functional limitations $(\mathrm{HR}=1.08,95 \%$ CI 1.03 to 1.14$)$, as well as experiencing any functional limitation $(\mathrm{HR}=1.47,95 \%$ CI 1.13 to 1.91 ) were all associated with statistically significant increases in the risk of other-cause mortality (table 2). Functional decline was not associated with other-cause mortality. When evaluating effect modification by stage, we found that the number of functional limitations $(\mathrm{HR}=1.11,95 \%$ CI 1.03 to 1.19$)$ as well as 0 vs $\geq 1$ functional limitations ( $\mathrm{HR}=1.46$, 95\% CI 1.05 to 2.03) were significantly associated with other-cause mortality in women with localised disease but not in those with regional or remote disease, whereas functional decline was associated with increased risk of othercause mortality in women with regional and remote disease $(\mathrm{HR}=1.61,95 \%$ CI 1.03 to 2.52$)$, but not in those with localised disease (table 3 ).

\section{Breast cancer-specific mortality}

Kaplan-Meier plots of breast cancer survival indicate that African-American women had poorer survival than white women (figure 2B, appendix). Furthermore, AfricanAmerican women with functional limitations had significantly poorer survival than those without limitations ( $p$ value for log-rank test $=0.05$ ). In multivariate models, we found no evidence of an association between any of the measures of functional limitations and breast cancerspecific mortality in this group (table 2). On the other hand, each unit of functional decline $(\mathrm{HR}=1.17,95 \%$ CI 1.05 to 1.31 ) and decline in the ability to sit $\geq 1 \mathrm{~h}$ $(\mathrm{HR}=2.06,95 \%$ CI 1.13 to 3.76$)$ were both significantly associated with increased risk of breast cancer mortality. Each unit increase in the number of functional limitations was positively associated with other-cause mortality in overweight (BMI 25-30; $\mathrm{HR}=1.17,95 \%$ CI 1.05 to 1.31 ) and obese women (BMI $>30 ; \mathrm{HR}=1.48,95 \%$ CI 1.09 to 2.02), but not in women of normal weight $(\mathrm{BMI}<25 ; \mathrm{HR}=1.13$, 95\% CI 0.94 to 1.36 ; table 3 ). Functional decline was positively associated with breast cancer mortality in obese women (HR=3.05, 95\% CI 1.32 to 7.03$)$.

\section{DISCUSSION}

We found that the presence of functional limitations after breast cancer diagnosis, including difficulties in mobility (walking half a mile) and in upper body 

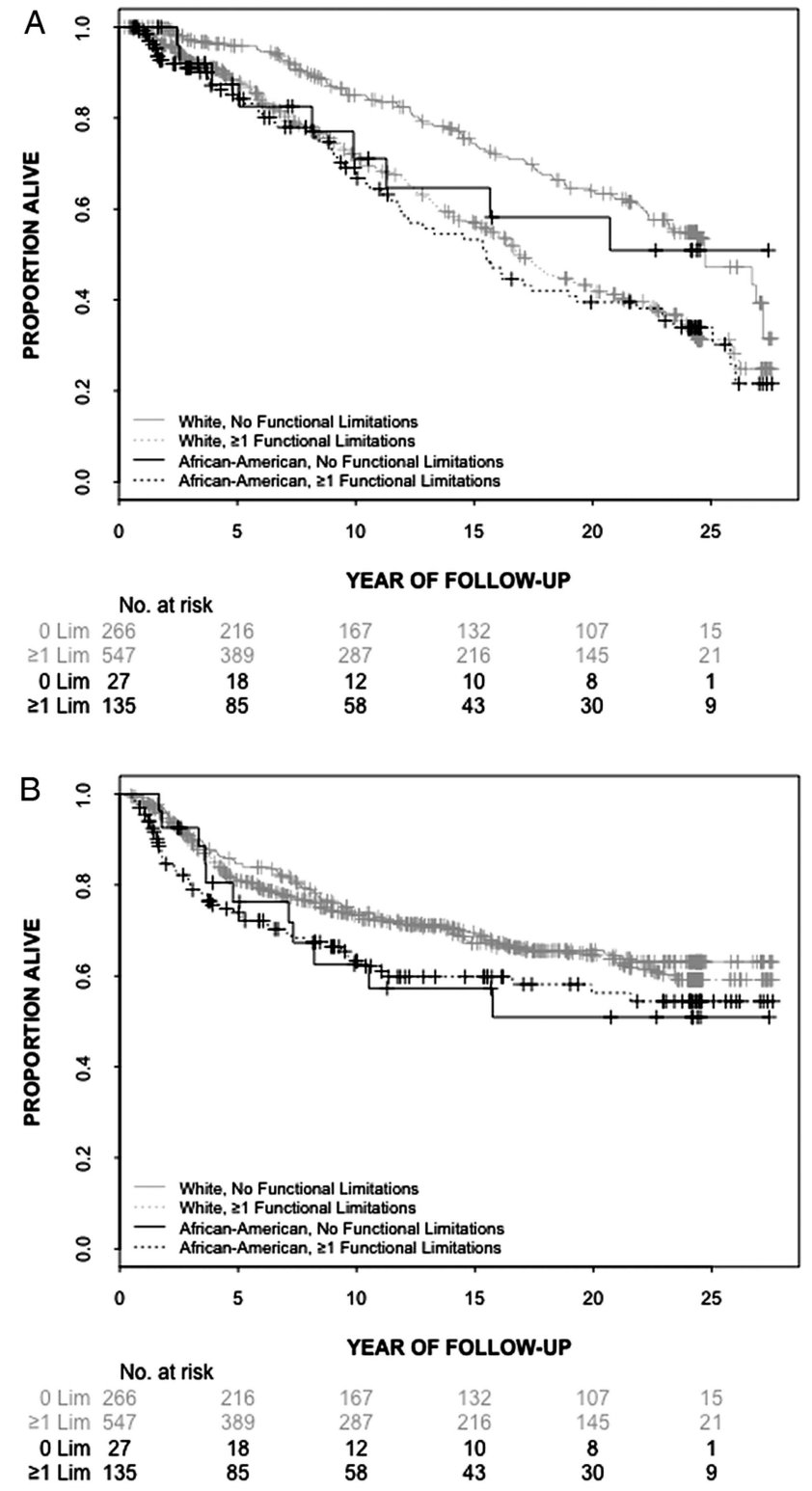

Figure 2 (A) Kaplan-Meier estimates of other-cause survival by race and category of functional limitations ( 0 vs $\geq 1)$. (B) Kaplan-Meier estimates of breast cancer survival by race and category of functional limitations ( 0 vs $\geq 1)$.

limitations (pushing or pulling large objects, and writing or handling small objects), was associated with statistically significant increases in the risk of other-cause mortality in this biracial cohort of breast cancer survivors. Overall, functional limitations were more prevalent among African-American women. Race was a significant predictor of mortality in univariate models, but the association was no longer significant in covariate-adjusted models. These findings suggest that factors other than functional limitations are responsible for racial disparities in the survival of women with breast cancer. In evaluating whether the effect of functional limitations varies across strata of breast cancer stages at diagnosis, we found that the presence of functional limitations was statistically significantly associated with other-cause mortality in women with localised disease, but not in women with regional and remote disease. Conversely, functional decline was associated with increased risk of other-cause mortality in women with regional and remote disease, but not in women with localised disease. Analyses stratified by BMI revealed that the number of functional limitations was positively associated with other-cause mortality in overweight and obese women, but not in women of normal weight. Each unit of functional decline and decline in lower body function (the ability to sit for an hour or longer) were both significantly associated with increased risk of breast cancer mortality. Functional decline was positively associated with breast cancer mortality in obese women. These findings underscore the prognostic role of obesity among breast cancer survivors.

This study extends earlier work that reported on the diminished quality of life and self-reported functional limitations as predictors of decreased overall and nonbreast cancer survival ${ }^{2} 25$ to show that limitations in lower body function and any functional decline during the first year after breast cancer diagnosis are strong predictors of breast cancer mortality. We found that functional decline has prognostic value for breast cancer independent of other prognostic factors and comorbidity; the impact of functional decline during the first year following breast cancer diagnosis is stronger in women with regional and remote disease. To our knowledge, this is the first study to evaluate the association of individual limitations and functional decline with survival among patients with breast cancer. Our findings underscore the predictive value of comprehensive measures of functional limitations.

Biological mechanisms by which functional limitations affect survival of patients with breast cancer are not well understood. Chronic inflammation has been linked to diminished physical functioning and disability in populations of older adults ${ }^{26-31}$ and may underlie the observed association of functional limitations with mortality. Functional limitations and cancer may synergistically increase inflammation resulting in disease progression and mortality. In this study, we have shown that functional limitations differentially impact breast cancerspecific and other-cause mortality. Specifically, we observed that functional limitations measured at baseline predicted other-cause mortality, particularly among non-obese women and those with localised disease. On the other hand, functional decline was associated with breast cancer-specific mortality, particularly among overweight and obese women. Prior to probing potential mechanisms linking physical functioning and causespecific mortality, these findings should be validated in other cohorts of breast cancer survivors by employing measures of functional limitations and other covariates, to verify the nature of the association between various aspects of physical functioning and cause-specific mortality. Identifying populations most likely to benefit from targeted interventions to enhance functional status is 
Table 2 HRs (and 95\% Cls) of functional limitations for mortality

\begin{tabular}{|c|c|c|c|c|}
\hline \multirow[b]{2}{*}{ Covariates } & \multicolumn{2}{|c|}{$\begin{array}{l}\text { Other-cause mortality (number of } \\
\text { deaths }=436 \text { ) }\end{array}$} & \multicolumn{2}{|c|}{$\begin{array}{l}\text { Breast cancer mortality (number of } \\
\text { deaths }=317 \text { ) }\end{array}$} \\
\hline & Baseline & Decline & Baseline & Decline \\
\hline \multicolumn{5}{|l|}{ Model 1} \\
\hline African-American & 1.23 (0.91 to 1.66$)$ & 1.19 (0.88 to 1.62$)$ & $1.04(0.76$ to 1.44$)$ & $1.08(0.78$ to 1.49$)$ \\
\hline \multicolumn{5}{|l|}{ Model 2} \\
\hline African-American & $1.19(0.87$ to 1.62$)$ & $1.19(0.88$ to 1.62$)$ & $1.12(0.81$ to 1.55$)$ & $1.08(0.78$ to 1.49$)$ \\
\hline Difficulty pushing/pulling large objects (yes/no) & 1.34 (1.04 to 1.73$)$ & 0.98 (0.67 to 1.43$)$ & 0.77 (0.58 to 1.03$)$ & 1.41 (0.93 to 2.13$)$ \\
\hline Difficulty stooping/crouching/kneeling (yes/no) & $1.02(0.77$ to 1.35$)$ & 0.97 (0.65 to 1.45$)$ & 1.39 (0.99 to 1.94$)$ & 0.94 (0.56 to 1.57$)$ \\
\hline Difficulty lifting less than 10 pounds (yes/no) & $0.92(0.68$ to 1.25$)$ & 0.91 (0.53 to 1.56$)$ & 1.05 (0.72 to 1.53$)$ & 1.27 (0.65 to 2.48$)$ \\
\hline Difficulty lifting $\geq 10$ pounds (yes $/ \mathrm{no}$ ) & 0.99 (0.75 to 1.30$)$ & $1.07(0.71$ to 1.60$)$ & 0.78 (0.56 to 1.07$)$ & $1.20(0.76$ to 1.89$)$ \\
\hline Difficulty extending arm above shoulder level (yes/no) & 0.97 (0.72 to 1.31$)$ & 0.94 (0.56 to 1.58$)$ & 0.85 (0.58 to 1.23$)$ & 0.92 (0.49 to 1.76$)$ \\
\hline Difficulty writing/handling small objects (yes/no) & 1.56 (1.00 to 2.44$)$ & $0.47(0.22$ to 1.03$)$ & 1.61 (0.95 to 2.73$)$ & 1.19 (0.53 to 2.68$)$ \\
\hline Difficulty standing more than $15 \mathrm{~min}$ (yes/no) & 0.81 (0.58 to 1.13$)$ & 1.33 (0.87 to 2.02$)$ & 0.91 (0.62 to 1.35$)$ & 1.58 (0.96 to 2.62$)$ \\
\hline Difficulty sitting more than an hour (yes/no) & 0.77 (0.49 to 1.22$)$ & 1.75 (0.99 to 3.09$)$ & 1.04 (0.63 to 1.73$)$ & 2.06 (1.13 to 3.76$)$ \\
\hline Difficulty going up/down a flight of stairs (yes/no) & $1.29(0.93$ to 1.78$)$ & $1.18(0.82$ to 1.69$)$ & 1.07 (0.70 to 1.63$)$ & 0.61 (0.37 to 1.01$)$ \\
\hline Difficulty walking half a mile (yes/ no) & 1.60 (1.19 to 2.14$)$ & $1.34(0.90$ to 2.00$)$ & 1.24 (0.88 to 1.77$)$ & 1.32 (0.82 to 2.13$)$ \\
\hline \multicolumn{5}{|l|}{ Model 3} \\
\hline African-American & $1.22(0.90$ to 1.65$)$ & $1.19(0.88$ to 1.61$)$ & 1.05 (0.76 to 1.44$)$ & 1.01 (0.73 to 1.40$)$ \\
\hline Functional limitations (continuous) & $1.08(1.03$ to 1.14$)$ & $1.10(1.00$ to 1.21$)$ & 0.99 (0.93 to 1.05$)$ & 1.17 (1.05 to 1.31$)$ \\
\hline \multicolumn{5}{|l|}{ Model 4} \\
\hline African-American & $1.17(0.87$ to 1.59$)$ & $1.21(0.90$ to 1.63$)$ & $1.08(0.78$ to 1.50$)$ & 1.04 (0.75 to 1.43$)$ \\
\hline Functional limitations ( $\geq 1$ vs 0 ) & 1.47 (1.13 to 1.91 ) & $1.17(0.92$ to 1.50$)$ & 0.75 (0.56 to 0.98 ) & $1.26(0.94$ to 1.69$)$ \\
\hline
\end{tabular}

*Models were stratified by age at breast cancer diagnosis and additionally adjusted for stage of comorbidity, breast cancer, treatment, body mass index, financial adequacy, education, smoking, positive lymph node involvement, tumour size at diagnosis and period of study entry. 
Table 3 HRs (and 95\% Cls) of functional limitations for mortality stratified by tumour stage and body mass index*

\begin{tabular}{|c|c|c|c|c|}
\hline & \multicolumn{2}{|c|}{$\begin{array}{l}\text { Other-cause mortality (number of } \\
\text { deaths }=436 \text { ) }\end{array}$} & \multicolumn{2}{|c|}{$\begin{array}{l}\text { Breast cancer mortality (number of } \\
\text { deaths }=317 \text { ) }\end{array}$} \\
\hline & Baseline & Decline & Baseline & Decline \\
\hline \multicolumn{5}{|l|}{ Stage of breast cancer at diagnosis* } \\
\hline Local, $\mathrm{N}=523$ & \multicolumn{2}{|c|}{ Number of deaths $=274$} & \multicolumn{2}{|c|}{ Number of deaths $=93$} \\
\hline Functional limitations (continuous) & $1.11(1.03$ to 1.19$)$ & $1.07(0.94$ to 1.23$)$ & $1.04(0.92$ to 1.17$)$ & $1.16(0.97$ to 1.38$)$ \\
\hline Functional limitations ( $\geq 1$ vs 0 ) & 1.46 (1.05 to 2.03$)$ & $1.06(0.75$ to 1.49$)$ & $1.30(0.76$ to 2.23$)$ & $1.02(0.59$ to 1.77$)$ \\
\hline Regional and remote, $\mathrm{N}=452$ & \multicolumn{2}{|c|}{ Number of deaths $=162$} & \multicolumn{2}{|c|}{ Number of deaths $=224$} \\
\hline Functional limitations (continuous) & $1.03(0.94$ to 1.14$)$ & $1.19(1.00$ to 1.43$)$ & $1.02(0.94$ to 1.10$)$ & $1.08(0.92$ to 1.26$)$ \\
\hline Functional limitations ( $\geq 1$ vs 0 ) & $1.58(0.90$ to 2.75$)$ & 1.61 (1.03 to 2.52$)$ & 0.66 (0.47 to 0.93$)$ & 1.19 (0.82 to 1.73$)$ \\
\hline \multicolumn{5}{|c|}{ Body mass index at baseline, $\left(\mathrm{kg} / \mathrm{m}^{2}\right) \dagger$} \\
\hline$<25, N=454$ & \multicolumn{2}{|c|}{ Number of deaths $=210$} & \multicolumn{2}{|c|}{ Number of deaths $=128$} \\
\hline Functional limitations (continuous) & 1.11 (1.01 to 1.22$)$ & $1.12(0.94$ to 1.32$)$ & $1.01(0.90$ to 1.14$)$ & $1.13(0.94$ to 1.36$)$ \\
\hline Functional limitations ( $\geq 1$ vs 0 ) & 1.80 (1.14 to 2.84$)$ & $1.45(0.93$ to 2.27$)$ & $0.74(0.46$ to 1.18$)$ & 1.00 (0.57 to 1.73$)$ \\
\hline $25-30, N=323$ & \multicolumn{2}{|c|}{ Number of deaths $=148$} & \multicolumn{2}{|c|}{ Number of deaths $=109$} \\
\hline Functional limitations (continuous) & 1.07 (1.02 to 1.13$)$ & $1.10(1.00$ to 1.21$)$ & 0.99 (0.93 to 1.06$)$ & $1.17(1.05$ to 1.31$)$ \\
\hline Functional limitations ( $\geq 1$ vs 0 ) & 1.48 (1.13 to 1.94$)$ & $1.24(0.95$ to 1.60$)$ & 0.71 (0.54 to 0.95$)$ & 1.28 (0.94 to 1.73$)$ \\
\hline$>30, N=198$ & \multicolumn{2}{|c|}{ Number of deaths $=78$} & \multicolumn{2}{|c|}{ Number of deaths $=80$} \\
\hline Functional limitations (continuous) & $0.78(0.60$ to 1.02$)$ & $1.09(0.68$ to 1.76$)$ & $1.08(0.92$ to 1.27$)$ & 1.48 (1.09 to 2.02$)$ \\
\hline Functional limitations ( $\geq 1$ vs 0 ) & $0.62(0.18$ to 2.12$)$ & $2.15(0.70$ to 6.60$)$ & $1.50(0.61$ to 3.66$)$ & 3.05 (1.32 to 7.03$)$ \\
\hline
\end{tabular}

the first step towards improving outcomes following breast cancer diagnosis.

In addition to our inability to address the underlying biological mechanisms, another important limitation of this study is that the majority of respondents were treated with partial or radical mastectomy, which is no longer the standard of care for early-stage breast cancer. The currently recommended standard of care for this population, consisting of radiation and segmental mastectomy or lumpectomy, may have less impact on function. Modern surgical techniques may also reduce the functional impact of breast cancer surgery. Furthermore, the observed patterns of functional limitations in this study may have been affected by the fact that a relatively small number of participants received adjuvant chemotherapy or hormone therapy. Although the self-reported nature of functional limitations in this study may be subject to bias, self-reported functional limitations have been shown to correlate with performance-based measures. ${ }^{10}$ Another limitation of the current study is our inability to compare whether women with breast cancer have a similar burden of functional limitations as women without breast cancer, and whether the impact of functional limitations on other-cause mortality differs in women with and without breast cancer.

The strengths of the study include comprehensive measures of functional limitations and functional decline, a prospective population-based cohort design, a relatively large set of white and African-American participants, a long follow-up and our ability to take into account multiple covariates in the tumour-related, lifestyle and sociodemographic domains. Since women in this study were identified through a large regional population-based surveillance programme, our findings may apply to wider audiences than studies in which participants were drawn from academic settings. Bias due to loss of follow-up was minimised because mortality status was ascertained annually for all the patients in the registry.

In summary, our findings indicate that functional limitations and functional decline during the first year following breast cancer diagnosis are associated with the breast cancer-specific and other-cause mortality of women with breast cancer.

Acknowledgements The authors would like to thank all women who participated in the study. The authors are grateful to Gloria Kwiatkowski and Fawn Vigneau from the Barbara Ann Karmanos Cancer Institute for their assistance with updating the mortality data.

Contributors WAS, as the principal investigator, established the cohort and led the data collection. Ml conducted statistical analyses, compiled findings and prepared the first draft of the manuscript. WAS and RAH participated in the writing of the manuscript. DB oversaw the concept, design, analysis and interpretation of the data and led the overall preparation of the manuscript. All authors approved the final draft of the manuscript.

Competing interests DB was supported by Grant \# KG110940 from Susan G Komen for the Cure and by Grant \# 121891-MRSG-12-007-01-CPHPS from the American Cancer Society for this research. In addition, WAS received support by Grant \# R01-AG04969 from the National Institute on Aging, and by Grant \# PBR-67 from the American Cancer Society.

Ethics approval This study was approved by the Committee on Human Research at the University of California, San Francisco. Additionally, the Health and Functioning in Women (HFW) study was approved at the time of its inception by the Human Subjects Committee at the Michigan Cancer Foundation.

Provenance and peer review Not commissioned; externally peer reviewed. 
Data sharing statement Data on the association of functional limitations and functional decline to all-cause mortality are also available to all interested parties. The authors have full control of all primary data and the Journal may review the data if requested.

Open Access This is an Open Access article distributed in accordance with the Creative Commons Attribution Non Commercial (CC BY-NC 3.0) license, which permits others to distribute, remix, adapt, build upon this work noncommercially, and license their derivative works on different terms, provided the original work is properly cited and the use is non-commercial. See: http:// creativecommons.org/licenses/by-nc/3.0/

\section{REFERENCES}

1. Given B, Given C, Azzouz F, et al. Physical functioning of elderly cancer patients prior to diagnosis and following initial treatment. Nurs Res 2001;50:222-32.

2. Braithwaite D, Satariano WA, Sternfeld B, et al. Long-term prognostic role of functional limitations among women with breast cancer. J Natl Cancer Inst 2010;102:1468-77.

3. Extermann M, Overcash J, Lyman $\mathrm{GH}$, et al. Comorbidity and functional status are independent in older cancer patients. J Clin Oncol 1998;16:1582-7.

4. Kroenke $\mathrm{CH}$, Rosner B, Chen WY, et al. Functional impact of breast cancer by age at diagnosis. J Clin Oncol 2004;22:1849-56.

5. Satariano WA, Ragheb NE, Branch LG, et al. Difficulties in physical functioning reported by middle-aged and elderly women with breast cancer: a case-control comparison. J Gerontol 1990;45:M3-11.

6. Satariano WA, Ragland DR. Upper-body strength and breast cancer: a comparison of the effects of age and disease. J Gerontol A Biol Sci Med Sci 1996;51:M215-19.

7. Patterson RE, Saquib N, Natarajan L, et al. Improvement in self-reported physical health predicts longer survival among women with a history of breast cancer. Breast Cancer Res Treat 2011;127:541-7.

8. Klepin HD, Geiger AM, Tooze JA, et al. Physical performance and subsequent disability and survival in older adults with malignancy: results from the health, aging and body composition study. J Am Geriatr Soc 2010;58:76-82.

9. Wenzel LB, Fairclough DL, Brady MJ, et al. Age-related differences in the quality of life of breast carcinoma patients after treatment. Cancer 1999;86:1768-74.

10. Ganz PA, Kwan L, Stanton AL, et al. Quality of life at the end of primary treatment of breast cancer: first results from the moving beyond cancer randomized trial. J Natl Cancer Inst 2004;96:376-87.

11. Ganz PA, Kwan L, Stanton AL, et al. Physical and psychosocial recovery in the year after primary treatment of breast cancer. $J$ Clin Oncol 2011;29:1101-9.

12. Sehl M, Lu X, Silliman R, et al. Decline in physical functioning in first 2 years after breast cancer diagnosis predicts 10-year survival in older women. J Cancer Surviv 2013;7:20-31.

13. Demark-Wahnefried W, Pinto BM, Gritz ER. Promoting health and physical function among cancer survivors: potential for prevention and questions that remain. J Clin Oncol 2006;24:5125-31.
14. Tammemagi CM, Nerenz D, Neslund-Dudas C, et al. Comorbidity and survival disparities among black and white patients with breast cancer. JAMA 2005;294:1765-72.

15. Tammemagi CM. Racial/ethnic disparities in breast and gynecologic cancer treatment and outcomes. Curr Opin Obstet Gynecol 2007;19:31-6.

16. Polednak AP. Racial differences in mortality from obesity-related chronic diseases in US women diagnosed with breast cancer. Ethn Dis 2004;14:463-8.

17. Carmichael AR. Obesity and prognosis of breast cancer. Obes Rev 2006;7:333-40.

18. Kerlikowske K, Walker R, Miglioretti DL, et al. Obesity, mammography use and accuracy, and advanced breast cancer risk. J Natl Cancer Inst 2008;100:1724-33.

19. Satariano WA, Ragland DR, DeLorenze GN. Limitations in upper-body strength associated with breast cancer: a comparison of black and white women. J Clin Epidemiol 1996; 49:535-44.

20. Nagi SZ. An epidemiology of disability among adults in the United States. Milbank Mem Fund Q Health Soc 1976;54:439-67.

21. Mariotto A, Feuer EJ, Harlan LC, et al. Trends in use of adjuvant multi-agent chemotherapy and tamoxifen for breast cancer in the United States: 1975-1999. J Natl Cancer Inst 2002; 94:1626-34

22. Satariano WA, Ragland DR. The effect of comorbidity on 3-year survival of women with primary breast cancer. Ann Intern Med 1994;120:104-10

23. Greenland S. Modeling and variable selection in epidemiologic analysis. Am J Public Health 1989;79:340-9.

24. Grambsch PM, Therneau TM. Proportional hazards tests and diagnostics based on weighted residuals. Biometrika 1994;81:515-26.

25. Arndt V, Merx H, Sturmer T, et al. Age-specific detriments to quality of life among breast cancer patients one year after diagnosis. Eur $J$ Cancer 2004;40:673-80.

26. Brinkley TE, Leng X, Miller ME, et al. Chronic inflammation is associated with low physical function in older adults across multiple comorbidities. J Gerontol A Biol Sci Med Sci 2009;64:455-61.

27. Ferrucci L, Penninx BW, Volpato $S$, et al. Change in muscle strength explains accelerated decline of physical function in older women with high interleukin-6 serum levels. J Am Geriatr Soc 2002;50:1947-54.

28. Ferrucci L, Harris TB, Guralnik JM, et al. Serum IL-6 level and the development of disability in older persons. J Am Geriatr Soc 1999;47:639-46.

29. Reuben DB, Cheh Al, Harris TB, et al. Peripheral blood markers of inflammation predict mortality and functional decline in high-functioning community-dwelling older persons. J Am Geriatr Soc 2002;50:638-44.

30. Taaffe DR, Harris TB, Ferrucci L, et al. Cross-sectional and prospective relationships of interleukin- 6 and C-reactive protein with physical performance in elderly persons: MacArthur studies of successful aging. J Gerontol A Biol Sci Med Sci 2000; 55:M709-15.

31. Zhu S, Patel KV, Bandinelli S, et al. Predictors of interleukin-6 elevation in older adults. J Am Geriatr Soc 2009;57:1672-7. 


\section{APPENDIX}

Table A1 $p$ Values for the log-rank tests comparing the survival distributions in figure $2 A, B$ by comparison groups

\begin{tabular}{|c|c|c|}
\hline Comparison groups & $\begin{array}{l}\text { Other-cause survival } \\
\text { (figure } 2 \mathrm{~A} \text { ) }\end{array}$ & $\begin{array}{l}\text { Breast cancer survival } \\
\text { (figure 2B) }\end{array}$ \\
\hline $\begin{array}{l}\text { African-American women with } \geq 1 \text { functional limitations vs } \\
\text { African-American women without functional limitations }\end{array}$ & $<0.0001$ & 0.50 \\
\hline $\begin{array}{l}\text { African-American women with } \geq 1 \text { functional limitations vs white women } \\
\text { with } \geq 1 \text { functional limitations }\end{array}$ & 0.06 & 0.05 \\
\hline $\begin{array}{l}\text { African-American women without functional limitations vs white women } \\
\text { without functional limitations }\end{array}$ & 0.15 & 0.20 \\
\hline $\begin{array}{l}\text { African-American women without functional limitations vs white women } \\
\text { with } \geq 1 \text { functional limitations }\end{array}$ & 0.84 & 0.33 \\
\hline $\begin{array}{l}\text { White women with } \geq 1 \text { functional limitations vs white women without } \\
\text { functional limitations }\end{array}$ & $<0.0001$ & 0.50 \\
\hline
\end{tabular}

